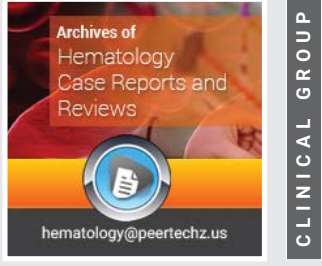

\title{
Immune thrombocytopenic
} purpura with subsequent development of JAK2 V617F-positive essential
thrombocythemia: Case Report

Received: 13 July, 2021

Accepted: 03 August, 2021

Published: 04 August, 2021

*Corresponding author: Marisabel Hurtado-Castillo, PGY-3, Internal Medicine, Department of Medicine at NYU, 536 Ovington Avenue Apartment 3, Brooklyn NYC 11209, USA, Tel: 718-312-9641;

Email: Marisabel.hurtadocastillo@nyulangone.org

Keywords: Immune thrombocytopenic purpura; Essential thrombocythemia; JAK-STAT signaling pathway; JAK2(V617F) mutation

https://www.peertechzpublications.com

\section{Check for updates}

\author{
Marisabel Hurtado-Castillo ${ }^{1 *}$, Brian Flaherty ${ }^{2}$ and Morris \\ $\mathrm{Jrada}^{2}$ \\ 1PGY-3, Internal Medicine, Department of Medicine at NYU, Brooklyn, NY, USA \\ ${ }^{2}$ Clinical Assistant Professor, Department of Medicine at NYU Grossman School of Medicine, Brooklyn, \\ NY, USA
}

\begin{abstract}
The sequential occurrence of Immune Thrombocytopenic Purpura (ITP) and Essential Thrombocythemia (ET) has been reported in the literature on a few occasions, as these are two hematologic disorders with distinct etiologies and patients usually have contrasting clinical presentations. Our case highlights the sequential occurrence of ITP, followed by Janus kinase 2 (JAK2) (V617F)-positive ET in a 64-year-old white woman, after four years of follow-up. The pathophysiology relating to these two conditions is incompletely understood, however, JAK2(V617F) mutation has been found in all the cases reported. Early identification of JAK2(V617F) mutation in a patient with a past medical history of ITP and presenting with thrombocytosis, may lead to a prompt diagnosis of ET and timely treatment initiation.
\end{abstract}

\section{Introduction}

Immune Thrombocytopenic Purpura (ITP) is an autoimmune pathology caused by autoantibodies directed against glycoproteins on the platelet surface causing peripheral destruction of platelets. Primary ITP is defined as isolated thrombocytopenia (platelet count $<100 \times$ $10^{9} / \mathrm{L}$ ) in the absence of other causes or disorders that may be associated with thrombocytopenia. Secondary ITP is defined as any form of ITP other than primary; these might include thrombocytopenia, secondary to systemic lupus erythematosus, chronic lymphocytic leukemia, HIV, hepatitis $\mathrm{C}$, or Helicobacter pylori infection [1]. Clinical presentation can be characterized by bruises following minor trauma, oral hemorrhagic bullae, epistaxis, gastrointestinal bleeding, conjunctival hemorrhage, or hematuria. Management depends on the severity of thrombocytopenia and bleeding. Treatment with glucocorticoids is indicated in all patients who present with bleeding and those with platelet counts less than $20 \times$ $10^{9} / \mathrm{L}[2]$.
Essential Thrombocythemia (ET) is one of the Myeloproliferative Neoplasms (MPNs) included in the World Health Organization (WHO) classification of tumors of hematopoietic and lymphoid tissues that also includes Chronic Myeloid leukemia (CML), Polycythemia Vera (PV), and Primary Myelofibrosis (PMF) [3]. ET is characterized by a sustained increase in platelet number greater than $450 \times 10^{9} / \mathrm{L}$ and tendency for thromboembolism. ET is also a diagnosis of exclusion, ruling out reactive (or secondary) thrombocytosis is essential, as this is the most common cause of thrombocytosis. Once reactive thrombocytosis is ruled out, a further diagnostic workup for ET is recommended. Testing can start with peripheral-blood screening to detect driver mutations, including Janus kinase 2 (JAK2) (V617F), Calreticulin (CALR) exon 9, and Myeloproliferative Leukemia virus oncogene (MPL) exon 10. Performing a bone marrow biopsy and aspiration rules out other MPNs and is required for a conclusive diagnosis of ET [4]. 
The detection of a driver mutation confirms the presence of a myeloid neoplasm, but the absence does not rule out this possibility because $10 \%$ of patients with ET can be triple-negative JAK2(V617F) mutation is present in around half of the patients with ET and divides the disease into two subtypes, $\mathrm{V} 617 \mathrm{~F}$-positive and $\mathrm{V} 617 \mathrm{~F}$-negative. ET treatment varies depending on patient age and driver mutation detected. In patients younger than 60 years old, without history of thrombosis or major bleeding and with platelet count less than $150 \times 10^{9} / \mathrm{L}$, low-dose aspirin is recommended only when JAK2 (V617F) mutation is detested or if CALR exon 9 mutation is detected and the patient also have at least 1 concomitant cardiovascular risk factor and/or with microvascular symptoms. By contrast, in patients older than 60 years old and/or history of thrombosis or major bleeding and/or with platelet count $\geq$ $150 \times 10^{9} / \mathrm{L}$, low-dose aspirin and cytoreductive therapy with interferon $\alpha$ or hydroxyurea is recommended regardless of the mutation status [4-6].

The sequential occurrence of two different types of platelet disorder as ITP and ET is rarely reported in the literature [7-10]. We report a case report JAK2(V617F)-positive ET in a patient previously diagnosed with ITP, after four years of follow-up.

\section{Case presentation}

A 64-year-old white woman with a past medical history of migraine headaches who was initially diagnosed with ITP in 2008 when she presented with a platelet count of $13 \times 10^{9} / \mathrm{L}$, the patient was treated with high dose dexamethasone with a normalization of the platelet count. In 2009, the patient was noted to have a platelet count of $2 \times 10^{9} / \mathrm{L}$ and was again treated with high dose dexamethasone with an improvement of the platelet count in the normal range after tapering off the steroids. The patient remained off steroids and had a normal platelet count until December 2011 when she was found to have sustained elevation of platelet count, her platelet count ranged from 290 to $580 \times 10^{9} / \mathrm{L}$, bone marrow biopsy was performed in February 2012 which showed a hypercellular marrow with increased large to giant megakaryocytes with abundant cytoplasm, hyperlobulated nuclei and occasionally megakaryocytes in clusters consistent with ET. A qualitative real-time polymerase chain reaction (RT-qPCR) analysis demonstrated the presence of JAK2(V617F) mutation. CALR exon 9, and MPL exon 10 mutations were not detected. The patient was initially treated with aspirin and later started on hydroxyurea for platelet count control when she had a transient ischemic attack, since then, the patient's platelet count has remained controlled, and she has not had any further thrombotic events.

\section{Discussion}

ITP and ET are two hematologic disorders with distinct etiologies and contrasting clinical presentations. We present a case of ITP with subsequent development of JAK2(V617F)positive ET, after four years of follow-up. There are only a few cases reported of ET in patients with a prior history of ITP $[9,10]$. The pathophysiology relating to these two conditions is incompletely understood, however, JAK2(V617F) mutation has been found in all the cases reported. JAK2(V617F) mutations constitutively activate JAK2, which in turn induces dysregulated phosphorylation of signal transducers and activators of transcription 3 and 5 (STAT3 and STAT5) [11].

The STAT5 pathway plays a critical role in the function and development of regulatory $\mathrm{T}$ cells (Tregs) [12]. Treg cells prevent autoimmune diseases by suppressing self-reactive $\mathrm{T}$ helper (Th) cells by several mechanisms including cytolysis, metabolic disruption, and production of inhibitory cytokines [13]. Therefore, consistently activated STAT 5 is associated with a suppression in antitumor immunity and induces the cell proliferation responsible for the neoplastic character of ET.

Activation of STAT3 is critically important for the development of myeloid cells, including affect dendritic cells (DC). However, some studies have shown that constitutive activation of STAT3 in hematopoietic progenitor cells results in the accumulation of $\mathrm{Gr}-1+\mathrm{CD} 11 \mathrm{~b}+$ in immature myeloid cells and DC differentiation is significantly impaired [14]. Authors suggested that JAK2(V617F) mutation and constitutive activation of JAK2/STAT3 signaling pathway might also affect DC differentiation, conducting to the production of antiplatelet autoantibodies which is a key pathogenetic mechanism of ITP. Further studies might be warranted to understand any potential similar pathogenetic mechanism between ITP and ET.

\section{Conclusion}

This case highlights a patient with a history of ITP presenting with thrombocytosis after four years of followup. It is imperative doing an early comprehensive workup of patients who present with isolated thrombocytosis. Once reactive thrombocytosis is ruled out, patients should be tested for JAK2(V617F), CALR exon 9, and MPL exon 10 mutations, and bone marrow biopsy and aspiration should be performed. Early identification of JAK2(V617F) mutation in a patient with a history of ITP and presenting with thrombocytosis, may lead to a prompt diagnosis of ET and timely treatment initiation.

\section{Data availability}

The data used to support the findings of this study are available from the authors upon request.

\section{References}

1. Rodeghiero F, Stasi R, Gernsheimer T, Michel M, Provan D, et al. (2009) Standardization of terminology, definitions and outcome criteria in immune thrombocytopenic purpura of adults and children: report from an international working group. Blood 113: 2386-2393. Link: https://bit.ly/3iiWPTq

2. Cines DB, Bussel JB (2005) How I treat idiopathic thrombocytopenic purpura (ITP). Blood 106: 2244-2251. Link: https://bit.ly/2Vu4aqt

3. Arber DA, Orazi A, Hasserjian R, Thiele J, Borowitz MJ, et al. (2016) The 2016 revision to the World Health Organization classification of myeloid neoplasms and acute leukemia. Blood 127: 2391-2405. Link: https://bit.ly/2Vmo3jg

4. Rumi E, Cazzola M (2016) How I treat essential thrombocythemia. Blood 128: 2403-2414. Link: https://bit.ly/3ypJP4e

5. Campbell PJ, Scott LM, Buck G, Wheatley K, East CL, et al. (2005) Definition of subtypes of essential thrombocythaemia and relation to polycythaemia vera

Citation: Castillo MH, Flaherty B, Jrada M (2021) Immune thrombocytopenic purpura with subsequent development of JAK2 V617F-positive essential thrombocythemia: Case Report. Arch Hematol Case Rep Rev 6(1): 018-020. DOI: https://dx.doi.org/10.17352/ahcrr.000033 
based on JAK2 V617F mutation status: a prospective study. Lancet (London, England) 366: 1945-1953. Link: https://bit.ly/37eziN8

6. Tefferi A, Pardanani A (2019) Essential Thrombocythemia. New England Journal Medicine 381: 2135-2144. Link: https://bit.ly/3jlL6mv

7. Farhat $M H$, Kuriakose $P$, Jawad M, Hanbali A (2012) Sequential occurrence of thrombotic thrombocytopenic purpura, essential thrombocythemia, and idiopathic thrombocytopenic purpura in a 42-year-old African-American woman: a case report and review of the literature. Journal of Medical Case Reports 6: 93. Link: https://bit.ly/2Vu3SzT

8. Oda Y, Sato S, Kanbe E, Kamata W, Okada S, et al. (2019) JAK2 V617Fpositive essential thrombocythemia with subsequent development of immune thrombocytopenia: A case report. Medicine 98: e17766. Link: https://bit.ly/3jaH9AY

9. Sobas MA, Wróbel T, Zduniak K, Podolak-Dawidziak M, Rybka J, et al (2017) Immune Thrombocytopenia and JAK2V617F Positive Essential Thrombocythemia: Literature Review and Case Report. Case Rep Hematol 2017: 3725089. Link: https://bit.ly/2ViWuY7
10. Caocci G, Atzeni S, Usai M, La Nasa G (2017) Essential thrombocytemia following immune thrombocytopenia with JAK2V617F mutation. Leukemia Research Reports 9: 14-15. Link: https://bit.ly/3rOaAwJ

11. Oku S, Takenaka K, Kuriyama T, Shide K, Kumano T, et al. (2010) JAK2 V617F uses distinct signalling pathways to induce cell proliferation and neutrophil activation. British Journal Haematology 150: 334-344. Link: https://bit.ly/3ikb3DB

12. Rani A, Murphy JJ (2016) STAT5 in Cancer and Immunity. Journal of Interferon Cytokine Research: 36: 226-237. Link: https://bit.ly/3rNOhqO

13. Vignali DA, Collison LW, Workman CJ (2008) How regulatory T cells work. Nature Reviews Immunology 8: 523-532. Link: https://go.nature. com/3rTF94a

14. Nefedova Y, Gabrilovich DI (2007) Targeting of Jak/STAT pathway in antigen presenting cells in cancer. Current Cancer Drug Targets 7: 71-77. Link: https://bit.ly/2VkA1tV

\section{Discover a bigger Impact and Visibility of your article publication with}

\section{Peertechz Publications}

\section{Highlights}

* Signatory publisher of ORCID

* Signatory Publisher of DORA (San Francisco Declaration on Research Assessment)

* Articles archived in worlds' renowned service providers such as Portico, CNKI, AGRIS, TDNet, Base (Bielefeld University Library), CrossRef, Scilit, J-Gate etc.

* Journals indexed in ICMJE, SHERPA/ROMEO, Google Scholar etc.

- OAI-PMH (Open Archives Initiative Protocol for Metadata Harvesting)

* Dedicated Editorial Board for every journa

* Accurate and rapid peer-review process

* Increased citations of published articles through promotions

* Reduced timeline for article publication

Submit your articles and experience a new surge in publication services (https://www.peertechz.com/submission).

Peertechz journals wishes everlasting success in your every endeavours.

Copyright: ( ) 2021 Castillo $\mathrm{MH}$, et al. This is an open-access article distributed under the terms of the Creative Commons Attribution License, which permits unrestricted use, distribution, and reproduction in any medium, provided the original author and source are credited.

Citation: Castillo MH, Flaherty B, Jrada M (2021) Immune thrombocytopenic purpura with subsequent development of JAK2 V617F-positive essential thrombocythemia: Case Report. Arch Hematol Case Rep Rev 6(1): 018-020. DOI: https://dx.doi.org/10.17352/ahcrr.000033 